\title{
Qual biblioteca universitária? Ações das bibliotecas universitárias mineiras e as necessidades informacionais de seus pesquisadores
}

\author{
Ana Carolina de Souza Caetano \\ Mestre; Universidade Federal de Juiz de Fora (UFJF); \\ acscaetano@yahoo.com.br \\ Geni Chaves Fernandes \\ Doutora; Universidade Federal do Estado do Rio de Janeiro (UNIRIO); \\ geni@ centroin.com.br
}

\begin{abstract}
Resumo: $\mathrm{O}$ artigo indaga sobre o atendimento das necessidades informacionais da pós-graduação e da pesquisa por bibliotecas universitárias, partindo da literatura recente do campo. Em um estudo investigativo em dez universidades federais mineiras, buscou-se mapear aspectos como: fontes de informação e seu acesso, atendimento da biblioteca, planejamento e ação da biblioteca. Os participantes foram estudantes e professores da pós-graduação e bibliotecários que atuam em três áreas do conhecimento. As análises dos resultados apontam a necessidade de uma política de informação para ciência e tecnologia, com destaque para o papel da biblioteca universitária em instituições federais. A sobrecarga de trabalho informacional por parte dos pesquisadores evidenciou a necessidade de uma Biblioteconomia à pesquisa. A capacitação dos bibliotecários, a constituição de infraestrutura para construção de repositórios institucionais acadêmicos, a elaboração de critérios para avaliação de bibliotecas acadêmicas, o desenvolvimento de coleções para pesquisa e pós-graduação, o planejamento de serviços, o auxílio na identificação e filtragem de recursos e a capacitação de usuários, o registro de políticas e meios de quantificação de seus efeitos, foram apurados como os principais caminhos para que a biblioteca universitária retome seu papel de coprodutora de conhecimento.
\end{abstract}

Palavras-chave: Bibliotecas universitárias. Biblioteconomia para pesquisa. Pósgraduação e pesquisa.

\section{Introdução}

Este trabalho tem como tema central as necessidades atuais de adequação das bibliotecas universitárias para o atendimento ao eixo de pesquisa (e pós-graduação), com base na literatura e em estudo empírico realizado junto aos bibliotecários e 
usuários das bibliotecas de universidades federais mineiras. Quis-se, a partir da literatura e da escuta dos diretamente envolvidos, mapear e discutir assuntos em tópicos que possam servir a uma agenda de discussões em vista da formulação de políticas públicas para bibliotecas universitárias no que diz respeito à sua participação efetiva no processo de pesquisa.

As instituições são construções sociais que correspondem (no sentido que respondem juntamente com outras) aos seus contextos, por meio através de normas e valores aceitos socialmente. Permeando a cultura e a educação, está a biblioteca enquanto instituição (MAGÁN WALS, 2001, 2004). Bibliotecas não são instituições isoladas, pertencem a um contexto histórico no qual são construídas nas diferentes formas de suas possibilidades de modo que, historicamente, as bibliotecas correspondem às demandas culturais e sociais vigentes (BATTLES, 2003; BURKE, 2003).

A biblioteca universitária é aquela mantida por uma instituição de ensino superior com a missão de atender toda a comunidade acadêmica: corpo docente, discente e administrativo nas esferas do ensino, da pesquisa e da extensão (CUNHA; CAVALCANTI, 2008; SANTOS; RIBEIRO, 2012). No caso brasileiro atual, devem atender ao planejamento, administração, organização e necessidades oriundas do tripé universitário, incluindo a comunidade acadêmica e a externa em geral, sendo partícipe e decisiva no processo educacional universitário, sem que possa ser delegado a outrem seu papel. Uma política bibliotecária efetiva e condizente à realidade só será bem sucedida com apoio da instituição universitária onde está instalada (FERREIRA, 1980).

Magán Wals (2001), em Temas de Biblioteconomía universitaria y general, trata do contexto social e educacional nesse início de século e como estes afetam e contribuem na condução dos procedimentos da biblioteca universitária. Além disso, coloca como um de seus destaques a prestação de serviços ao pesquisador, dado que o acesso ao conhecimento tem valor agregador, incluindo-se hoje a prestação de serviço online nas bibliotecas, adicionando novos valores aos que já possui, por meio de consórcios e parcerias com outras instituições.

Pensando nas bibliotecas como coprodutoras de conhecimento, para Magán 
Wals (2004) a chamada sociedade do conhecimento e suas exigências conduzem as bibliotecas para uma crise frente ao seu papel social e às possibilidades de serviços ofertados e controle e difusão informacional. Se os usuários não estão frequentando as bibliotecas, isso não significa que eles deixaram de existir, mas que a biblioteca não se adaptou aos novos meios que seus usuários estão utilizando.

Retrocedendo ao nascimento do Seminário Nacional de Bibliotecas Universitárias (SNBU), na sua primeira edição em 1978 já se podia observar a consciência de adequar a biblioteca às demandas da pesquisa e da pós-graduação. Dentre os painéis havia um intitulado "A biblioteca universitária e os programas de pós-graduação" que contou com 11 apresentações. A questão central apresentada nesse painel foi o bibliotecário como especialista no auxílio aos pesquisadores em suas atividades. A biblioteca universitária apresentada como um "centro vital da cadeia de informação" e nela o profissional especializado, com conhecimentos próprios à organização, seleção e difusão do conhecimento (GUIMARÃES, 1979).

Esberard (1979) ressaltava o papel da biblioteca de ensinar estudantes a serem críticos e saberem pesquisar. Igualmente diziam que a biblioteca universitária, do ponto de vista do pesquisador, era aquela que fazia com que seu planejamento e política fossem adequados às áreas de conhecimento de suas instituições, por meio de obtenção de recursos de qualidade científica para evitar duplicidade de esforços e materiais.

A professora Laszlo (1979) falou da sua impressão sobre a biblioteca universitária e o imaginário que dela se tem. O desenvolver de seu texto demonstra sua sensibilidade para com a importância dos registros do conhecimento:

\footnotetext{
Quando entro numa biblioteca, o ambiente de silêncio, respeito e multidão de livros e periódicos me transmitem um estado de espírito de quase religiosidade. Uma biblioteca é, para mim, um congresso permanente de estudiosos. Nas estantes, como se estivessem reunidos em poltronas imaginárias, estão presentes os sábios de todas as épocas e países. Nas publicações encontram-se todos os tesouros da sabedoria: a herança cultural do passado, os progressos científicos e tecnológicos do presente e as previsões do futuro (LASZLO, 1979, p. 393).
}

Para Laszlo, a leitura é a grande chave para desvendar os tesouros escondidos nessa respeitabilidade que se pressente na biblioteca, denominando-a de 
"casa master" dos que se dedicam à pesquisa e ao magistério.

Granja (1979) apontava o papel das bibliotecas universitárias em países desenvolvidos como centros de informação. Para retratar a realidade brasileira, e indicar caminhos, apresentou um diagnóstico para as bibliotecas da Universidade de São Paulo (USP) e concluiu que estas não operavam enquanto centros de informação, por falta de estrutura e investimentos.

As falas desses docentes convidados para o I SNBU e a inclusão do tema pós-graduação nos painéis do evento demonstram que já muito se pensou no papel da biblioteca universitária à luz das necessidades da pesquisa. Contudo, esta temática desapareceu nas edições posteriores do seminário.

Passados 26 anos da edição do PNBU (Programa Nacional de Bibliotecas Universitárias), é mais do que tempo de repensar as bibliotecas universitárias e indagar, no quadro do novo século, como as bibliotecas universitárias têm atendido ao projeto de produção de novos conhecimentos, considerando-se as visíveis transformações no âmbito da produção de conhecimentos e, no caso brasileiro, a concentração da pesquisa e pós-graduação em universidades públicas (CAETANO, 2014).

Partiu-se da literatura do campo em artigos de periódicos brasileiros de Qualis A e B da Base de Dados Referencial de Artigos de Periódicos em Ciência da Informação (Brapci), do Encontro Nacional de Pesquisa em Ciência da Informação (Enancib), além de artigos estrangeiros da College and Research Libraries (CRL), da Association of College and Reserach Libraries (ACRL), da American Library Association (ALA) e da base de dados E-Prints in Library and Information Science (e-LiS) para uma primeira aproximação das ações, demandas e limitações atuais destas bibliotecas. Também foram utilizados os trabalhos dos SNBU. O levantamento abarcou os últimos dez anos.

Na pesquisa de campo optou-se por um recorte que observa a ação e serviços das bibliotecas universitárias mineiras, em instituições públicas de ensino, do ponto de vista dos bibliotecários e dos usuários, por meio de questionários enviados entre os meses de julho e agosto de 2013 a pós-graduandos e pesquisadores docentes das áreas de Ciências Agrárias, Ciências da Saúde e Sociais Aplicadas e aos 
bibliotecários de todas as áreas do conhecimento de dez universidades federais ${ }^{1}$, para indagar sobre a ação, a efetividade e as limitações atuais destas bibliotecas.

\section{Bibliotecas universitárias na literatura do campo}

As bibliotecas universitárias vêm sendo alvo de reflexões e, a fim de problematizálas, é importante verificar o que dela está em questão nos âmbitos acadêmico e profissional. Os principais apontamentos foram colocados em destaque.

A missão da biblioteca inclui ações que proporcionam a produção de novos conhecimentos. Conforme Anzolin e Corrêa (2008), essa missão se evidencia quando ela é mediadora na produção do conhecimento, fornecendo subsídios para reflexão, pesquisa, formação de capital intelectual e geração de novos conhecimentos. Carvalho (2006) considera que as políticas públicas de informação precisam contemplar interesses nacionais, tendências internacionais e a capacidade de produção do conhecimento. Isto exige infraestrutura e ambiente de pesquisa organizados, principalmente nas universidades e centros de pesquisa. Para González de Gómez (2011) essas bibliotecas têm a potencialidade de participar ativamente da produção científica acadêmica em todas as suas etapas. Mas como se adequar para atender a estas expectativas?

Para Schwartz (2007), o desenvolvimento de coleções para a pesquisa só se realiza em consonância com os objetivos da universidade. Entretanto, embora deva ter papel decisivo no ambiente acadêmico, a biblioteca não participa das decisões institucionais, sendo importante repensar este relacionamento, pois muitos problemas que atrapalham seu funcionamento adequado são oriundos da falta de diálogo entre as partes.

Gaspar e Wetzel (2009), em pesquisa realizada na George Washington University, apontam os bons resultados do trabalho cooperativo entre docentes, alunos e bibliotecários que no intervalo de um semestre se reuniram para debater sobre as pesquisas acadêmicas em curso visando definir a contribuição da biblioteca nestes contextos. A ação trouxe efeitos na qualidade dos textos produzidos na universidade pesquisada e no incentivo aos alunos para trabalharem em equipe. 
Tarango e Hernández-Orozco (2009) consideram que a biblioteca universitária deve se reinventar, com independência suficiente para contribuir na educação superior. Assim, para que avalie o grau real de sua independência, propõem avaliações periódicas: da biblioteca, do progresso bibliotecário e do desenvolvimento da biblioteca. Baptista, Rueda e Santos (2008) apontam para o problema da avaliação, ou falta de avaliação, das bibliotecas universitárias feitas por um instrumento avaliativo que ignora o papel e as possibilidades de contribuição das mesmas, além de se preocupar simplesmente com o aspecto quantitativo de seus acervos

Para Varela et al. (2012), devido às atuais tecnologias, a biblioteca universitária nem sempre atua como mediadora das fontes de informação científica, já que seu acesso pode ocorrer diretamente. Mas esse fato não é negativo, uma vez que é apenas uma das consequências do uso da tecnologia no mundo científico. A missão da biblioteca universitária ganharia aí sentidos mais profundos, como a de potencialização do conhecimento, integrando as funções do tripé universitário, operando no "[...] habitus de aprendizagem contínua e de internalização da atitude científica." (VARELA et al., 2012, documento eletrônico não paginado).

Explorando a relação educação-biblioteca, Gómez-Hernandez (2013) trata da capacitação permamente do profissional bibliotecário. Na realidade espanhola, a partir dos anos 1980 os cursos de graduação diminuíram consideravelmente e os programas de pós-graduação sofreram processo contrário. As bibliotecas acadêmicas tiveram que se adaptar à nova realidade e dentre as ações realizadas estiveram os cursos para ampliar a competência informacional de docentes e bibliotecários, investimento em serviços online e criação de repositórios institucionais, demonstrando o interesse dos bibliotecários em participar do processo de aprendizagem universitário (GÓMEZ-HERNANDEZ, 2013).

A biblioteca universitária também precisa se adaptar para atender a educação a distância (EAD). Trata-se de não somente fornecer suporte aos alunos para que dele façam uso, mas também para integrar comunidade acadêmica, presencial e semipresencial do EAD (NASCIMENTO, 2008). Segundo o documento $n^{\circ} 5.622$ do Ministério da Educação (MEC) (BRASIL, 2005), as bibliotecas dos polos devem 
conter um acervo amplo, com mídias variadas, serviços online de atendimento e espaço físico de estudo individual e em grupo. Porém, isso exige habilidades com as novas mídias. O problema é que no Brasil ainda não se dispõe de documentos que orientem os bibliotecários da educação a distância. Nos Estados Unidos, a ALA disponibiliza o Standards for Distance Learning Library Services, edição de 2008, para nortear as bibliotecas acadêmicas nos procedimentos administrativos e biblioteconômicos na EAD (AMERICAN..., 2008).

Com a expansão da pós-graduação entre as décadas de 1970 e 1980, os docentes passaram a ter carreira acadêmica e as universidades a serem instituições produtoras de pesquisa (SANTOS, 2012). Nasser, Dantas e Amaral (2008) acreditam que a biblioteca seja um eixo de sustentação do ensino e pesquisa universitários e, em pesquisa realizada junto aos docentes, identificaram que estes utilizam mais os serviços online, mas desejariam que houvesse mais capacitação para seu uso e dos serviços clássicos, além da divulgação ampla sobre o que a biblioteca pode oferecer à comunidade.

Silva, Silva e Guerrero (2008) apresentam resultados de pesquisa sobre a competência informacional de mestrandos da área de humanidades de universidades paulistas. $\mathrm{O}$ resultado revela que os mestrandos não conheciam as fontes especializadas de suas áreas, tinham dificuldades em recuperar informações pertinentes, não desenvolveram maiores habilidades de busca no fim do mestrado e tinham hábito de procurar o bibliotecário quando não obtinham sucesso em suas pesquisas.

Portanto, fica evidente a demanda de participação ativa e consciente do profissional bibliotecário em todas as etapas da produção científica acadêmica, cuja viabilização e acompanhamento carecem de políticas públicas que incluam as políticas para estas bibliotecas com processos específicos de avaliação (gerais e locais), capacitação e atualização profissional frente ao ambiente contemporâneo. Os trabalhos dos SNBU apontam à percepção de mudanças significativas na educação superior que precisam ser acompanhadas. A avaliação, a dificuldade na formação e o desenvolvimento de coleções, assim como os novos formatos de EAD e a preocupação com a competência informacional são questões identificadas como 
relevantes para discutir o papel atual destas bibliotecas.

\section{Necessidades informacionais e ações da biblioteca universitária: estudo investigativo}

A análise do tema agrupa elementos comuns relativos aos agentes sociais pesquisados, evidenciando as ações da biblioteca no atendimento às necessidades informacionais dos pesquisadores. Os questionários e a compilação das respostas estão disponíveis no estudo de Caetano (2014). No quadro abaixo estão dados informativos da estimativa do universo pesquisado e das respostas obtidas no estudo.

As respostas dos três grupos participantes foram agrupadas dentro dos seguintes tópicos: Papel da biblioteca para pesquisa e pós-graduação; O conhecimento do usuário de pós-graduação e pesquisa pela biblioteca; Mediação no âmbito da pesquisa; Entendimento das necessidades da pesquisa e pós-graduação; Repositórios institucionais; Desenvolvimento de Coleções; Capacitação de usuários e auxílio na identificação de fontes. Os conjuntos de respostas em cada tópico foram confrontados entre os grupos e analisados com base no marco teórico e apoio na literatura da área e se encontram logo após o quadro.

Quadro 1 - Dados gerais do estudo investigativo

\begin{tabular}{|c|c|c|c|}
\hline & ALUNOS & DOCENTES & BIBLIOTECÁRIOS \\
\hline $\begin{array}{l}\text { PORCENTAGEM } \\
\text { DE } \\
\text { PARTICIPAÇÃO }\end{array}$ & $\begin{array}{l}\text { Estimativa } 6.000 \\
\text { Participantes } 118 \\
(\mathbf{1 , 9 6 \% )}\end{array}$ & $\begin{array}{l}\text { Estimativa } 1381 \\
\text { Participantes } 113 \\
(\mathbf{8 , 1 8 \% )} \\
\end{array}$ & $\begin{array}{l}\text { Estimativa } 77 \\
\text { Participantes } 22(\mathbf{2 9 \%})\end{array}$ \\
\hline $\begin{array}{l}\text { ÁREAS E } \\
\text { INSTITUIÇÕES } \\
\text { QUE MAIS } \\
\text { CONTRIBUIRAM }\end{array}$ & $\begin{array}{lr}\text { Ciências } & \text { Sociais } \\
\text { Aplicadas e } & \text { Ciências } \\
\text { Agrárias: } & \text { UFMG, } \\
\text { UFLA e UFU } & \\
\end{array}$ & $\begin{array}{l}\text { Ciências da Saúde } \\
(56,6 \%) \\
\text { UFMG, UFV e UFU }\end{array}$ & $\begin{array}{l}\text { Biblioteca multidisci-plinar } \\
\text { ou central, Ciências Exatas } \\
\text { e Ciências Humanas: UFJF, } \\
\text { UFOP, UFVJM }\end{array}$ \\
\hline $\begin{array}{l}\text { DESEMPENHO } \\
\text { DE FUNÇÃO }\end{array}$ & & $\begin{array}{l}66,3 \% \text { não é/ não foi } \\
\text { coordenador e/ou diretor } \\
\text { de curso e/ou progr. de } \\
\text { pós-graduação }\end{array}$ & $\begin{array}{l}63,6 \% \text { gestão/ adm. e } \\
\text { proces. Técnico; } \\
\text { Atendimento presencial } \\
54,5 \% \text { e virtual } 22,7 \% \text {. }\end{array}$ \\
\hline $\begin{array}{l}\text { TEMPO MÉDIO } \\
\text { DE RESPOSTA }\end{array}$ & $\begin{array}{l}62,7 \% \text { responderam nos } \\
10 \text { dias iniciais. Tempo } \\
\text { médio de resposta: } 10 \text { a } \\
20 \text { min. }\end{array}$ & $\begin{array}{l}86,7 \% \text { responderam nos } \\
10 \text { dias inicias. Tempo } \\
\text { médio de resposta: } 10 \text { a } \\
20 \text { min. }\end{array}$ & $\begin{array}{l}63,6 \% \text { responderam nos } 10 \\
\text { dias iniciais Tempo médio } \\
\text { de resposta: } 20 \text { a } 25 \text { min. }\end{array}$ \\
\hline
\end{tabular}

Fonte: elaborado pelas autoras.

Nota: UFMG: Universidade Federal de Minas Gerais; UFLA: Universidade Federal de Lavras; UFU:

Universidade Federal de Uberlândia; UFV: Universidade Federal de Viçosa; UFJF: Universidade

Federal de Juiz de Fora; UFVJM: Universidade federal dos Vales do Jequitinhonha e Mucuri.

Qual biblioteca universitária? Ações das bibliotecas universitárias mineiras e as necessidades 


\subsection{Papel da biblioteca para a pós-graduação}

A análise dos resultados indicou que $68,2 \%$ dos discentes e $71,1 \%$ dos docentes consideraram o atendimento de suas bibliotecas bom ou ótimo. O dado está fortemente relacionado com as respostas referentes às possibilidades de acesso à informação por via institucional, mesmo que se infira, no conjunto das respostas e como se verá nas análises adiante, que o papel da biblioteca está aquém do desejado.

As fontes de informação, apesar de algumas lacunas apontadas, não aparecem como um entrave à pesquisa. A dificuldade apontada é na identificação dos recursos. Estudantes e pesquisadores consideraram todas as fontes indicadas no questionário como relevantes para suas pesquisas (e ainda incluíram outras), destacando-se os periódicos, livros e bases de dados, cujo acesso se dá por meio da própria instituição. Os pesquisadores sabem disso e embora haja algumas queixas de docentes relativas ao acesso a alguns títulos de periódicos e a estatísticas fornecidas por instituições públicas dos acessos por discentes, ambos consideram-se satisfeitos com o acervo disponível.

Ainda que as lacunas não cheguem a constituir um obstáculo significativo à pesquisa, inesperadamente pesquisadores não consideram a biblioteca como o lugar para onde podem encaminhar suas demandas informacionais. Para grande parte dos pesquisadores a biblioteca é um lugar onde se pode acessar o acervo existente, mas não um lugar em que se pode contar com serviços de identificação e aquisição de materiais que atendam às pesquisas.

Propôs-se aos entrevistados docentes e discentes opções de ação para a biblioteca $^{2}$ em vista de torná-las mais adequadas às atividades de pesquisa, mesmo que todas as opções tenham sido consideradas importantes, destacou-se como mais significativo o trabalho biblioteconômico de suporte. Entende-se este suporte como ações que agilizem e auxiliem a pesquisa em suas diversas etapas e por diferentes fluxos de informação, o que poderíamos chamar de uma "Biblioteconomia para pesquisa". O rastreamento e localização de recursos é a demanda que se destaca e reforça a expectativa do trabalho biblioteconômico junto à pesquisa.

É bastante provável que a necessidade de ajuda na identificação e organização de informações para pesquisa se deva à sobrecarga de trabalho 
informacional que incide sobre pesquisador. As dificuldades para gerir estas informações aliadas a estarem atualizados com novos instrumentos e bases científicas fica evidente.

\subsection{O conhecimento do usuário de pós-graduação e pesquisa pela biblioteca}

O estudo de usuários é um importante meio para conceber, com um mínimo de detalhes, o escopo da biblioteca, não devendo ser encarado como supérfluo ou secundário. É um instrumento chave para conhecer a comunidade acadêmica (NASSER; DANTAS; AMARAL, 2008) e pode ser realizado considerando os usuários individualmente ou grupos de usuários (área do conhecimento, cursos, linhas ou grupos de pesquisa), permitindo traçar perfis que são fundamentais para a elaboração de quase todas as políticas da biblioteca. Os usuários das bibliotecas que responderam aos questionários consideram majoritariamente seus programas como o usuário da biblioteca, seguido de pesquisadores e estudantes de pós-graduação entendidos individualmente.

Se os pesquisadores não reconhecem a biblioteca como o lugar para onde podem enviar demandas de recursos informacionais, a biblioteca também desconhece seus perfis e necessidades, já que em $45 \%$ responderam não haver registros destes estudos e 35\% das bibliotecas não souberam informar.

Assim, 80\% das bibliotecas não planejam o atendimento conforme este estudo, mas $20 \%$ os realizam. Entretanto, parece haver uma desconexão entre o que os bibliotecários consideram como perguntas para tal mapeamento e o que os pesquisadores consideram serem perguntas com esta finalidade, já que os docentes afirmam que nunca responderam à biblioteca sobre suas necessidades de informação.

Em seguida, abriu-se espaço para justificativas ou comentários. Os bibliotecários indicaram que o atendimento a pesquisadores é feito conforme as demandas presenciais ou virtuais, já que o quadro de pessoal é muito reduzido para realizar estudos de usuários, ou foi feito um estudo há mais de quatro anos. Para Araújo (2003), esse é um dos fatores que mais tem atrapalhado na propagação de 
informações. A justificativa do reduzido quadro de recursos humanos aponta a precariedade do trabalho técnico de tratamento documental feito sem conhecer o usuário e por isso sem políticas norteadoras. $\mathrm{O}$ que impede que a biblioteca realize estes estudos e monitoramentos? Podem-se elencar algumas hipóteses, mas, sejam quais forem, o fato não deixa de ser preocupante, pois se o planejamento antecede a ação, o contrário poderá ser desastroso.

Quando se solicitou que os bibliotecários identificassem quem eram seus usuários de pesquisa e pós-graduação, as opções menos apontadas foram "grupos de pesquisa", "linhas de pesquisa" e "programas de pós-graduação". A identificação dos usuários individuais contrasta com a resposta dos próprios usuários que identificaram o "programa” como o principal usuário da biblioteca.

\subsection{Mediação no âmbito da pesquisa}

Observando os resultados do estudo investigativo, de modo geral, dos três grupos de agentes participantes, ressalta-se que a opção "Não sei informar", resposta constante em todas as perguntas do questionário nas temáticas abordadas, aparece em percentuais consideráveis. Estudantes e docentes em geral desconhecem os serviços, produtos e potencialidades da biblioteca universitária e os profissionais que atuam nesta área desconhecem as necessidades informacionais dos pesquisadores. São evidências de problemas de comunicação entre as partes que deve afetar substancialmente o desempenho esperado da biblioteca universitária, comprometendo a produção e disseminação do conhecimento científico.

Certamente a falta de estudo de usuários está no cerne do problema da mediação, mas também faltam canais adequados. Em nosso estudo, 90\% das bibliotecas afirmaram possuir canais de comunicação com os usuários, além do contato presencial. Mas o mútuo desconhecimento indica que estes meios não são adequadamente utilizados, ou precisam ser repensados, já que discentes da pósgraduação sabem que podem ir à biblioteca, física ou virtualmente, para obter informações para suas pesquisas, entretanto, têm uma percepção patrimonialista da biblioteca ao invés de uma percepção de mediadora no acesso à informação. 
Os docentes, ao contrário dos estudantes, atuam na universidade por um longo período de tempo. O fato de quase metade dos participantes desconhecer para onde deve encaminhar suas demandas pode indicar que os docentes não buscam auxílio para resolverem suas necessidades de informação. Sozinhos tentam localizar aquilo que precisam, já que quase a metade disse não saber a quem encaminhar suas demandas por fontes de informação. A questão da mediação no âmbito da pesquisa se articula com o próximo tema de releitura dos resultados, que é o entendimento do processo de pesquisa e que implica no diferencial de necessidades informacionais.

\subsection{Entendimento das necessidades da pesquisa e pós-graduação}

As bibliotecas têm potencialidade para participar ativamente da produção científica acadêmica em todas as suas etapas (GONZÁLEZ DE GÓMEZ, 2011). Entretanto, o entendimento do processo de pesquisa, da comunicação científica, do papel das fontes e dos usos da informação são os primeiros passos na estruturação dos serviços. A pesquisa indicou, em vários momentos, senão um entendimento frágil do que seja o usuário pesquisador ao menos um tratamento genérico e indiferenciado de usuários.

Em relação aos anais de eventos, por exemplo, o primeiro acesso registrado a resultados de pesquisa, apenas $18,1 \%$ dos bibliotecários indicaram manter tais acervos atualizados. O fato da biblioteca não monitorar os eventos relevantes para os programas de pós-graduação pode ser considerado como um indicativo da falta de entendimento sobre o papel deste tipo documental na pesquisa, do que são a própria pesquisa e a comunicação científica. Essa não compreensão se confirma quando os bibliotecários apontaram que não os adquirem porque os programas não solicitam aquisição de anais e um dos prováveis motivos do porquê isto ocorre é porque a maioria dos docentes e discentes não sabe a quem encaminhar suas demandas.

Tal desconhecimento não se trata apenas de um problema para as bibliotecas que estão apagadas no seu papel, mas para a própria pesquisa, já que se pode inferir que docentes e estudantes consideram-se desassistidos e acabam assumindo a atividade de obtenção de informação como uma tarefa exclusivamente sua, sem 
poder contar com mediadores. Isto certamente compromete uma parcela significativa de tempo que poderia ser canalizada para a atividade fim.

Apesar de a maioria das bibliotecas dispor de acesso à Biblioteca Digital de Teses e Dissertações (BDTD), coordenada pelo Instituto Brasileiro de Informação em Ciência e Tecnologia (IBICT), um meio de divulgação da produção científica institucional, é preocupante que haja um percentual de quase $30 \%$ das universidades mineiras que não a tenham. Isto invisibiliza os resultados de pesquisa dos programas e interfere negativamente na produção de novos conhecimentos.

O periódico é ainda o principal meio de comunicação formal na ciência. As bibliotecas universitárias pesquisadas têm pouca influência no desenvolvimento das coleções de periódicos oferecidos pelo Portal de Periódicos da Capes, que são a principal fonte de pesquisa. Os critérios utilizados no desenvolvimento desta grande coleção (RODRIGUES, 2008) podem não contemplar pesquisas e programas específicos. Considera-se que um maior envolvimento dos bibliotecários que atendem aos programas de pós-graduação, com a identificação de recursos de periódicos relevantes e a discussão de meios que permitam maior precisão na seleção, pode aperfeiçoar o acesso e uso destas importantes fontes. Mas apenas oferecer o Portal de Periódicos da Capes não deixa de ser um apagamento da biblioteca em uma oferta baseada em critérios quantitativos e generalistas.

O desconhecimento com relação às linhas de pesquisa e aos projetos em andamento podem implicar em um desenvolvimento de coleções que não supra às necessidades reais da pós-graduação. Além disso, observou-se a aquisição de coleções à parte pelas pós-graduações, sem identificação e tratamento por bibliotecários, o que podem implicar em aquisições duplicadas e acesso restrito.

Os bibliotecários têm consciência que o modelo de tratamento igualitário para todos os alicerces do tripé universitário não seja o adequado e esperado. A personalização do atendimento é uma urgência nos serviços e produtos que a biblioteca universitária se dispõe a oferecer.

Há indicativos de que a formação e/ou atualização do bibliotecário compreender e poder trabalhar mais adequadamente no serviço à pós-graduação é um aspecto a ser discutido. Cursos de especialização ou mestrado podem contemplar 
atualizações nos estudos sobre os processos de pesquisa (e certamente outros que auxiliem nos outros alicerces do tripé universitário).

\subsection{Repositórios institucionais}

O conhecimento científico produzido na universidade pública é um bem público que precisa ser socializado: é base para a construção de novos conhecimentos e uma prestação de contas à sociedade. $\mathrm{Na}$ divulgação da pesquisa científica, a mediação de editoras comerciais nem sempre segue princípios sociais, incorporando-se aí o lucro, com restrição ao conhecimento via acesso pago (MIGUÉIS et al., 2012).

A ideia de construção de repositórios institucionais é fruto do Movimento de Acesso Livre que opera com três princípios: o autoarquivamento, a revisão pelos pares e a interoperabilidade. $\mathrm{O}$ primeiro busca garantir os direitos do autor e inserilo na participação ativa de alimentação de uma base de dados institucional, o segundo objetiva assegurar a fidedignidade e qualidade dos conteúdos e o último se preocupa com a disseminação e compartilhamento das informações (SWAN, 2012).

Nos repositórios, a disponibilização dos resultados da produção científica é rápida, pois o próprio autor pode submeter o seu texto ao repositório, tendo sido avaliado, mas ainda não disponibilizado pela revista.

Weitzel (2006b, p. 62) aponta como uma das vantagens dos repositórios a visibilidade pela não obrigatoriedade do intermediário na comunicação científica. Para Miguéis et al. (2012), os repositórios institucionais articulam-se ao movimento que visa a difusão da literatura científica preservando e maximizando o impacto das pesquisas. A participação das bibliotecas no movimento de acesso aberto pode colocá-las como "editoras" dos repositórios, já que contribuem na reunião e organização das coleções (MÁGAN WALS, 2001).

O estudo também revelou que mais de $75 \%$ dos docentes e alunos consideram o repositório institucional importante e acreditam serem os bibliotecários e/ou a biblioteca os profissionais e/ou setor mais adequado para gestão do mesmo. Porém as respostas dos estudantes indicam um frágil entendimento do que seja o repositório e seu papel. 
Além de fornecer visibilidade, os repositórios permitem mapear o desenvolvimento das pesquisas em cada instituição, a trajetória de pesquisadores, o desenvolvimento de temas, dentre outras possibilidades. Mas na atualidade nas universidades brasileiras, sua efetividade depende de ações do Estado, dentre elas a obrigatoriedade de autoarquivamento dos resultados de pesquisas financiadas com recursos públicos (chamados de mandatórios), ressalvados os direitos autorais e de copyright, e viabilização do instrumental tecnológico que permita interoperabilidade entre os diversos repositórios.

Aponta Henning (2013) que a infraestrutura e interoperabilidade dependem de articulações que deveriam estar ao encargo de uma entidade central. Repositórios sem mandatórios de arquivamento por parte dos pesquisadores são pouco viáveis, além disso, o simples mandatório, sem uma infraestrutura que organize as entradas para futuras pesquisas, tenderia mais a uma justaposição de trabalhos e metadados de trabalhos que permitem buscas limitadas. A organização dos documentos no repositório é fundamental para possibilitar tanto o alavancamento de novas pesquisas quanto, e associado a isso, servir de instrumento para gestão do conhecimento dentro da instituição.

Henning (2013) também identifica a lei de direitos autorais como um dos entraves à organização da informação nos repositórios institucionais, inclusive para cópias sem fins lucrativos. Portanto, a temática do repositório é relevante, especialmente para as áreas de conhecimento em que as barreiras ao acesso estão solidamente fincadas em interesses econômicos das editoras.

Portanto, a temática do repositório é relevante, especialmente para as áreas de conhecimento onde as barreiras ao acesso estão solidamente fincadas em interesses econômicos das editoras. Mas é preciso que o Estado veja na pesquisa científica brasileira e nos seus resultados objetos de políticas públicas que incluem os repositórios. Ou seja, a construção e gestão do repositório como tarefa exclusiva da biblioteca, sem ancoragem em uma política pública ampla para pesquisa, enfrenta entraves.

Identificou-se na pesquisa de campo que docentes têm mais clareza da relevância do repositório do que estudantes. Já para os bibliotecários, curiosamente, 
os repositórios estão entre os assuntos menos importantes, carecendo de investigação. Possivelmente, isso se deve à falta de conhecimento do atual processo de produção de conhecimento, agregando ainda mais dificuldades para sua construção e gestão dentro das universidades federais. A concepção dos repositórios e o papel dos bibliotecários na sua gestão é uma temática importante para se discutir modos de viabilização em formatos de repositórios efetivos "de" e "para" pesquisa.

\subsection{Desenvolvimento de coleções}

Para Schwartz (2007), a política de desenvolvimento de coleções deve ser construída tendo em vista as metas da instituição, incorporando a tríade universitária. Para a gestão e consonância das fontes de informação científica com a pós-graduação e a pesquisa, a existência e efetiva aplicação da Política de Desenvolvimento de Coleções (PDC) são primordiais. Os novos tipos documentais também implicam na diversificação das coleções, seu acompanhamento e articulação.

O estudo de usuários permite traçar perfis fundamentais para a elaboração de quase todas as políticas da biblioteca, incluindo-se aí a PDC (FIGUEIREDO, 1998; WEITZEL, 2006a). Portanto, a falta destes estudos, conforme levantado nesta pesquisa, implica em um deficiente desenvolvimento das coleções.

Dos bibliotecários respondentes, $45 \%$ são especializados na área de conhecimento que a biblioteca atende e devem conhecer seus principais conceitos e fontes de informação, seguidos de $40 \%$ das bibliotecas em que isso não ocorre. Com bibliotecários mais especializados e capacitados ao diálogo nas áreas em que atuam, o atendimento à pesquisa poderia perceber resultados positivos (GONZÁLEZ DE GÓMEZ, 2011).

Como já indicado, 70\% dos estudantes e docentes da pós-graduação afirmaram nunca terem participado de um estudo de usuários e os bibliotecários confirmam esta preocupante realidade. O mesmo percentual de bibliotecários afirma oferecer treinamento à pós-graduação, ou seja, os bibliotecários pesquisados supõem quais sejam as fontes que docentes e alunos dos programas de pós-graduação necessitem. É possível que suas inferências sejam razoáveis, entretanto seria mais 
adequado procurar saber dos próprios usuários quais realmente são as suas necessidades informacionais.

Cerca de $65 \%$ dos bibliotecários que responderam ao questionário afirmaram que as PDC estão em desenvolvimento. Sem considerar quem usa as coleções e suas prioridades elas correm o risco de serem concebidas a partir de suposições que nem sempre dizem respeito à realidade. A biblioteca estaria se desenvolvendo para si mesma, com base em seus pressupostos e não no seu contexto, ou seja, não correspondendo às demandas de seu tempo. Seria como se ela ainda estivesse seguindo as diretrizes do PNBU e sua situação ainda fosse a dos anos de 1980.

\subsection{Capacitação de usuários e auxílio na identificação de fontes}

É preocupante que boa parte das bibliotecas capacite da mesma forma a graduação e a pós-graduação. As demandas por informação não são as mesmas, as necessidades e usos são diferentes. Além disso, há de se ter em conta que a demanda de informação vai além da capacitação, porque o auxílio, mesmo para o que sabe manejar os instrumentos de uma base de dados, apareceu na pesquisa como necessidade tanto de discentes quanto de docentes.

Como os pesquisadores consideraram, na sua maioria, o atendimento oferecido pela biblioteca como bom ou ótimo, é bastante provável que a demanda por ajuda na identificação e na organização de informações, de acordo as respostas dos pesquisadores e estudantes de pós-graduação, se deva à sobrecarga informacional que sobre eles incide, conforme já identificado por Schwartz (2007).

Parece haver uma internalização por parte do pesquisador de que a busca de fontes de informação e sua gestão é de sua responsabilidade exclusiva, ou quase. Entretanto, as atividades de busca e gerenciamento colocam-se, nas perguntas posteriores, como um problema a ser resolvido (demanda por ajuda). É possível que os modos de acesso remoto direto tenham fornecido ao pesquisador maior autonomia, mas seria prudente indagar o que esta autonomia acarreta quiçá estar desassistido diante de tantas opções e até que ponto isto não tem implicado num apagamento da biblioteca relativamente às suas potencialidades de serviços à 
pesquisa e à pós-graduação.

Também é possível que os bibliotecários considerem não ser necessário auxiliar aos pesquisadores, cabendo a eles, especialmente com os atuais meios de acesso, buscarem e organizarem de modo próprio seus acervos. Neste caso o bibliotecário não se coloca como mediador, mas considera que apenas os instrumentos devem cumprir este papel. A falta de recursos humanos nas bibliotecas universitárias é uma questão que muito afeta o planejamento e suas ações, contudo, se não há instrumentos para identificação de fontes de informação necessárias, não adianta ter recursos para adquiri-las.

\section{Considerações finais}

Nossa investigação apontou para a não adequada sintonia da biblioteca com as necessidades informacionais dos pesquisadores mineiros. Há falta de comunicação, diálogo e de realização de estudos de usuários e de usos da informação.

O estudo investigativo evidenciou que pesquisadores e estudantes de pósgraduação mineiros não conhecem efetivamente as potencialidades da biblioteca universitária e que os bibliotecários têm consciência destas, mas, por motivos variados (burocracia, falta de infraestrutura e de recursos humanos adequados, falta de proatividade, falta de cobrança por parte do Estado) não as exploram.

As queixas de desassistência e o desamparo dos pesquisadores e pósgraduandos também sugerem a carência de atualização de conhecimentos por parte dos bibliotecários dos atuais modos de produção de conhecimento, tanto no plano da comunicação científica quanto nos desdobramentos práticos do acesso remoto não mediado em relação aos pesquisadores. Tal carência faz com que não fique claro o importante papel a ser desempenhado pela biblioteca e pelos bibliotecários na produção de conhecimento acadêmico.

A igualação dos serviços da biblioteca para a comunidade acadêmica é um indicativo desta falta de atualização dos bibliotecários. As avaliações do MEC dos cursos de graduação concentram, sobretudo, as atenções em meios para atender à graduação que não são adequados para a pós-graduação. Falta preparo aos 
bibliotecários a fim de desenvolverem ações para a pesquisa que, conforme os resultados obtidos, referem-se mais ao auxílio na identificação, seleção de material relevante do que na disponibilização e acessibilidade dos acervos.

Ainda nesta perspectiva de atualização e preparo dos bibliotecários, há a inclusão, num traçado mais abrangente, de uma política de informação para ciência e tecnologia. Seu escopo será mais amplo, mas certamente precisarão incluir as bibliotecas de universidades federais. A participação com competência e conhecimento destes bibliotecários (bibliotecas) no traçado desta política é fundamental, sua não inclusão implica em insistir na ilusão da eficácia do acesso não mediado, aumentando-se os custos (de recursos e tempo) em identificação e recuperação de informação para pesquisa e despotencializando a capacidade produtiva da pesquisa no país.

Certamente, as tecnologias de informação e comunicação superdimensionaram a disponibilidade de acesso e novos tipos documentais, além de facilitarem a comunicação informal. Aí também apareceram, ao contrário da perspectiva inicial de acesso a tudo, de um lado, as barreiras monetárias de alguns periódicos em algumas áreas do conhecimento e o movimento de livre acesso como resposta e resistência a tais barreiras e de outro, uma sobrecarga para todos nas atividades informacionais envolvidas.

Destacam-se, no contexto contemporâneo, os repositórios institucionais como uma das respostas de enfrentamento aos desafios atuais de acesso à informação para a pesquisa (e extensão e divulgação).

Repositórios institucionais devem ser um capítulo de destaque no desenho de uma política de informação para $\mathrm{C} \& \mathrm{~T}$ e não podem prescindir somente das bibliotecas tanto na elaboração de seu desenho como na sua execução já que docentes, especialmente, e discentes indicaram sua relevância. A ação isolada de estruturação de repositórios institucionais em IES, conforme o quadro atual é um indicativo da falta de entendimento e da inércia do Estado em relação aos atuais problemas e modo de produção do conhecimento científico.

Sem dúvida a falta de compreensão mais ampla também aparece nas respostas dos bibliotecários a esta pesquisa, que consideraram os repositórios como 
tema de menor relevância. Apesar disso, repositórios geridos por bibliotecas dependem também de claro discernimento dos bibliotecários de seu papel hoje.

Embora os repositórios possam ser vistos como patrimônio da produção intelectual da instituição, eles não podem ser desenhados e geridos numa perspectiva patrimonialista. As múltiplas possibilidades de utilização dos repositórios precisam ser contempladas em seu desenho, assim como os meios para garantir sua manutenção e a interoperabilidade entre repositórios de diferentes instituições acadêmicas que contemplem as mesmas áreas ou campos de pesquisa.

$\mathrm{O}$ acesso rápido e não mediado pela biblioteca, que indicava agilidade, com o tempo parece levar à sobrecarga o trabalho de pesquisadores e pós-graduandos. A não identificação da biblioteca como lugar para enviarem suas demandas de informação deixa clara a urgência de um reexame da biblioteca na medida em que deixou de lado o seu papel de coprodutora de conhecimentos.

As pessoas continuam precisando do acompanhamento e do auxílio para buscar registros do conhecimento que lhes interessem e as tecnologias de informação e comunicação não as fez mais independentes das contribuições da organização e representação do conhecimento, atividades tão caras e inerentes ao trabalho bibliotecário. Pelo contrário, as TICs potencializaram e impactaram a quantidade e qualidade dos registros do conhecimento e na produção documental, científica ou não, o que demanda mais colaboração com o pesquisador e leitor.

\section{Referências}

AMERICAN Library Association. Standards for distance learning library services. Jul. 2008. Disponível em:

<http://www.ala.org/acrl/standards/guidelinesdistancelearning>. Acesso em: 03 abr. 2013.

ANZOLIN, Heloisa Helena; CORRÊA, Rosa Lydia Teixeira. Biblioteca universitária como mediadora na produção de conhecimento. Revista Diálogo

Educacional, Curitiba, v. 8. n. 25, p.801-817, set./dez. 2008. Disponível em: <http://www2.pucpr.br/reol/index.php/DIALOGO?dd1=146>. Acesso em: $06 \mathrm{fev}$. 2013. 
ARAÚJO, Eliany Alvarenga de. Informação pública: paradoxos e desafios. Informação \& Informação, Londrina, v. 8, n. 2, 2003. Disponível em: $\langle$ http://www.brapci.ufpr.br/documento.php?dd0=0000004348\&dd1 $=91059$ >. Acesso em: 28 mar. 2013.

BAPTISTA, Rafael; RUEDA, Daniela; SANTOS, Nadia Bernuci. A biblioteca universitária no contexto das avaliações do MEC: uma reflexão. In: SEMINÁRIO NACIONAL DE BIBLIOTECAS UNIVERSITÁRIAS, 15., 2008, São Paulo. Anais... São Paulo: UNICAMP, 2008. Disponível em: <http://www.sbu.unicamp.br/snbu2008/anais/site/pdfs/3274.pdf >. Acesso em: 25 mar. 2013.

BATTLES, Matthew. A conturbada história das bibliotecas. São Paulo: Planeta, 2003.

BRASIL. Presidência da República. Casa Civil. Decreto no 5.622, de 19 de dezembro de 2005. Regulamenta o art. 80 da Lei n. 9.394, de 20 de dezembro de 1996, que estabelece as diretrizes e bases da educação nacional. Brasília, 2005. Disponível em: <http://portal.mec.gov.br/seed/arquivos/pdf/dec_5622.pdf〉. Acesso em: 06 ago. 2012.

BURKE, Peter. Uma história social do conhecimento: de Gutemberg a Diderot. Rio de Janeiro: Jorge Zahar, 2003.

CAETANO, Ana Carolina de Souza. Discussão de uma agenda pública para bibliotecas universitárias federais: o foco na pós-graduação e pesquisa pelo olhar mineiro. 2014. Dissertação (Mestrado em Biblioteconomia) - Escola de Biblioteconomia, Universidade Federal do Estado do Rio de Janeiro, Rio de Janeiro, 2014.

CARVALHO, Kátia de. Disseminação da informação no âmbito da pesquisa e o papel dos organismos de fomento. DataGramaZero, v. 7, n. 2, 2006. Disponível em: 〈http://www.brapci.ufpr.br/documento.php?dd0=0000003723\&dd1=5fcdb>. Acesso em: 27 mar. 2013

CUNHA, Miriam Vieira da; CAVALCANTI, Córdelia Robalinho de Oliveira. Dicionário de Biblioteconomia e Arquivologia. Brasília: Briquet de Lemos/Livros, 2008.

ESBERARD, Charles Alfred. A biblioteca universitária no Brasil do ponto de vista do pesquisador, suas expectativas e interesses. In: SEMINÁRIO NACIONAL DE BIBLIOTECAS UNIVERSITÁRIAS, 1., 1978, Niterói. Anais... Niterói: Núcleo de Documentação/UFF, 1979. p. 373-377.

FERREIRA, Lusimar Silva. Bibliotecas universitárias brasileiras. São Paulo: Pioneira, 1980. 
FIGUEIREDO, Nice Menezes. Desenvolvimento e avaliação de coleções. 2. ed. rev. e atual. Brasília: Tesauros, 1998.

GASPAR, Debora; WETZEL, Karen A. A case study in collaboration: assessing academic librarian/faculty partnerships. College and Research Libraries, Chicago, v. 70, n. 6, p. 578-591, nov.2009. Disponível em:

<http://crl.acrl.org/content/70/6/578. short>. Acesso em: 28 mar. 2013.

GÓMEZ-HERNANDEZ, José-Antonio. Unir educación y bibliotecas: la evolución de un reto permanente. El profesional de la información, Barcelona, v. 22, n. 2, p. 101-105, mar./abr. 2013. Disponível em:

<http://elprofesionaldelainformacion.metapress.com/media/bav097bntjcxtp8aekdw/c ontributio ns/b/3/r/3/b3r34ju865344k18.pdf>. Acesso em: 06 abr. 2013.

GONZALEZ DE GÓMEZ, Maria Nélida. A universidade e a sociedade da informação. Revista Digital de Biblioteconomia e Ciência da Informação, Campinas, v. 9, n. 1, p. 225-242, jul./dez. 2011. Disponível em:

<http://www.sbu.unicamp.br/seer/ojs/index.php/rbci/article/viewFile/510/pdf_11>. Acesso em: 16 ago. 2012.

GRANJA, Elza Corrêa. A biblioteca universitária e seus reflexos na pesquisa científica. In: SEMINÁRIO NACIONAL DE BIBLIOTECAS UNIVERSITÁRIAS, 1., 1978, Niterói. Anais... Niterói: Núcleo de Documentação/UFF, 1979. p. 396-402.

GUIMARÃES, Jorge da Silva Paula. A biblioteca universitária no Brasil do ponto de vista do pesquisador, suas expectativas e interesses. In: SEMINÁRIO NACIONAL DE BIBLIOTECAS UNIVERSITÁRIAS, 1., 1979, Niterói. Anais... Niterói: Núcleo de Documentação/UFF, 1979.

HENNING, Patrícia Corrêa. Micro e macropolíticas de informação: o acesso livre à informação científica no campo da saúde no Brasil e em Portugal. 2013. $234 \mathrm{f}$.

Tese (Doutorado em Informação e Comunicação em Saúde) - Instituto de Comunicação e Informação Científica e Tecnológica em Saúde, Fundação Oswaldo Cruz, Rio de Janeiro, 2013. Disponível em: <http://www.arca.fiocruz.br/handle/icict/6998>. Acesso em: 09 dez. 2013.

LASZLO, Herta. A vinculação entre a biblioteca universitária e os cursos de pósgraduação. In: SEMINÁRIO NACIONAL DE BIBLIOTECAS

UNIVERSITÁRIAS, 1., 1978, Niterói. Anais... Niterói: Núcleo de Documentação/UFF, 1979. p. 393-395.

MAGÁN WALS, José Antonio (Coord.). Temas de Biblioteconomía universitária y general. Madrid: Editorial Compultense, 2001.

MAGÁN WALS, José Antonio. Tratado básico de Biblioteconomía. 5. ed. Madrid: Editorial Complutense, 2004. 
MIGUÉIS, Ana et al. Alguns aspetos da utilização do estudo geral: efeitos associados ao depósito de documentos. In: CONFERÊNCIA LUSO-BRASILEIRA SOBRE ACESSO ABERTO, 3., 2012. Lisboa. Anais... Lisboa, 2012. Disponível em: 〈https://estudogeral.sib.uc.pt/handle/10316/20700〉. Acesso em: 09 dez. 2012.

NASCIMENTO, Aline Vieira. Desafios da biblioteca universitária diante do avanço do ensino superior à distância no Brasil. In: SEMINÁRIO NACIONAL DE BIBLIOTECAS UNIVERSITÁRIAS, 15., 2008, São Paulo. Anais... São Paulo: UNICAMP, 2008. Disponível em:

<http://www.sbu.unicamp.br/snbu2008/anais/site/pdfs/3178.pdf>. Acesso em: 25 mar. 2013.

NASSER, Jane Cury; DANTAS, Jefferson Higino; AMARAL, Sueli Angélica do. Comportamento dos docentes do programa de pós-graduação em administração (PPGA) da Universidade de Brasília na busca e uso da informação. In:

SEMINÁRIO NACIONAL DE BIBLIOTECAS UNIVERSITÁRIAS, 15., 2008, São Paulo. Anais... São Paulo: UNICAMP, 2008. Disponível em:

〈http://www.sbu.unicamp.br/snbu2008/anais/site/pdfs/2935.pdf>. Acesso em: 22 de setembro de 2013.

RODRIGUES, Kátia de Oliveira. Mudanças nas práticas de desenvolvimento de coleções de periódicos científicos nas bibliotecas universitárias brasileiras. 2008, 160 f. Dissertação (Mestrado em Ciência da Informação) - Programa de Pósgraduação em Ciência da Informação, Universidade Federal da Bahia, Salvador, 2008. Disponível em:

〈https://repositorio.ufba.br/ri/bitstream/ri/7936/1/Katia_Rodrigues_2.pdf>. Acesso em: 12 fev. 2013.

SANTOS, Gildenir Carolino; RIBEIRO, Célia Maria. Acrônimos, siglas e termos técnicos: Arquivística, Biblioteconomia, Documentação, Informática. 2. ed. rev. ampl. Campinas: Átomo, 2012.

SANTOS, Marivaldina Bulcão dos. Biblioteca universitária: acesso à informação e conhecimento. In: SEMINÁRIO NACIONAL DE BIBLIOTECAS UNIVERSITÁRIAS, 17., 2012, Gramado. Anais... Gramado: UFRGS, 2012. Disponível em: 〈http://www.snbu2012.com.br/anais/pdf/4QHV.pdf〉. Acesso em: 24 mar. 2013.

SCHWARTZ, Charles A. The university library and the problem of knowledge. College \& Research Libraries, Chicago, v. 68, n. 3, p. 238-245, May 2007. Disponível em: 〈http://crl.acrl.org/content/68/3/238.full.pdf+html>. Acesso em: 20 mar. 2013.

SILVA, Helen de Castro; SILVA, Marli Vítor; GUERRERO, Janaína Celoto. Avaliação do nível de competência em informação de pós-graduandos da área de humanidades. In: SEMINÁRIO NACIONAL DE BIBLIOTECAS UNIVERSITÁRIAS, 15., 2008, São Paulo. Anais... São Paulo: UNICAMP, 2008. 
Disponível em: 〈http://www.sbu.unicamp.br/snbu2008/anais/site/pdfs/3028.pdf>. Acesso em: 19 mar. 2013.

SWAN, Alma. Policy guidelines for the development and promotion of open access. Paris: UNESCO, 2012. Disponível em: $<$ http://unesdoc.unesco.org/images/0021/002158/215863e.pdf>. Acesso em: 11 nov. 2013.

TARANGO, Javier; HERNÁNDEZ-OROZCO, Guillermo. Evaluación de bibliotecas universitarias: un modelo de avance y desarrollo. Revista Interamericana de Bibliotecología, Medellin, v. 32, n. 2, p. 147-175, Jul.-Dic. 2009. Disponível em: 〈http://eprints.rclis.org/17039/1/4421.pdf〉. Acesso em: 22 mar. 2013.

VARELA, Aida Varela et al. Potencializando a atitude científica mediante o desenvolvimento de competências informacionais: missão da biblioteca universitária. In: ENCONTRO NACIONAL DE PESQUISA EM CIÊNCIA DA INFORMAÇÃO, 13., 2012, Rio de Janeiro. Anais... Rio de Janeiro: ANCIB, 2012. Disponível em:

<http://www.eventosecongressos.com.br/metodo/enancib2012/arearestrita/pdfs/1955 9.pdf>. Acesso em: 04 dez. 2012.

WEITZEL, Simone. Elaboração de uma política de desenvolvimento de coleções em bibliotecas universitárias. Rio de Janeiro: Interciência: Niterói: Intertexto, 2006a.

WEITZEL, Simone. O papel dos repositórios institucionais e temáticos na estrutura da produção científica. Em Questão, Porto Alegre, v. 12, n. 1, p.51-71, jan./jun. 2006 b. Disponível em: <http://seer.ufrgs.br/index.php/EmQuestao/article/view/19/7>. Acesso em: 20 maio 2013.

\section{What university library? Activities of Minas Gerais University libraries and the informational needs of its researchers}

\footnotetext{
Abstract: This article investigate on the solution of informational needs of research and postgraduate studies by university libraries and starts from the recent literature of the field. In an investigative study in ten federal universities of Minas Gerais, we seek to draw aspects such as: sources of information and its access, the library customer service and library planning and action. Where interviewed postgraduate students, professors and librarians of three areas of knowledge. The study of data points the necessity of an information policy for science and technology, with emphasis on the role of the university library in federal institutions. The overload of information work by researchers highlights the need of a library allied to research. The training of librarians, the creation an infrastructure that can construct academic Qual biblioteca universitária? Ações das bibliotecas universitárias mineiras e as necessidades 
institutional repositories, the development of criteria for evaluation of academic libraries, the development of collections for research and postgraduate studies, a service planinng, assistance in identifying and filtering of data and informational training of users, the record of library policies and means of quantifying their effects were determined as the main pathways for the university library to reassume its role as co-producer of knowledge.

Keywords: University libraries. Library for research. Post graduation and research.

Recebido: 06/10/2014

Aceito: 04/02/2015

${ }^{1}$ Minas Gerais possui onzes universidades federais ao todo, porém uma não possui cursos das áreas de conhecimento delimitadas no estudo investigativo.

${ }^{2}$ Ações propostas: "Auxílio na filtragem, organização e seleção de informações, dados, documentos das minhas áreas de interesse"; "Atualização das novidades no acervo físico e digital sobre assuntos relacionados à minha pesquisa"; "Constituição e manutenção de repositório institucional [...]"; "Disponibilidade para acompanhar e adequar a prestação de serviços às necessidades das linhas de pesquisa que participo"; "Disponibilidade para acompanhar e adequar a prestação de serviços às necessidades dos grupos de pesquisa que participo"; "Disponibilidade para acompanhar e adequar a prestação de serviços às necessidades do meu programa de pósgraduação"; "Capacitação no uso de bases de dados". 